\title{
Canard-Elevon Interactions on a Hypersonic Vehicle
}

\author{
Torstens Skujins* and Carlos E. S. Cesnik \\ University of Michigan, Ann Arbor, Michigan 48109 \\ and \\ Michael W. Oppenheimer: and David B. Domans \\ U.S. Air Force Research Laboratory, Wright-Patterson Air Force Base, Ohio 45433
}

DOI: $\underline{10.2514 / 1.44743}$

\begin{abstract}
Airbreathing hypersonic cruise vehicles are typically characterized by long, slender bodies with highly coupled engines and airframes. For a case in which the engine is underslung (below the center of gravity), a large elevon control surface is typically necessary to trim the vehicle. The elevon is usually placed at the rear of the vehicle to yield a large moment arm. However, the drawback is that the elevons can cause large perturbations in lift and other undesirable effects. Canard control surfaces are placed on the forebody of the vehicle to counteract these effects as well as aid in low-speed handling. This study looks at how the canards affect the flow over the elevon control surfaces and, in turn, the controllability of the vehicle in general. A two-dimensional analytical formulation is developed and compared with both a series approximation solution and a computational fluid dynamics Euler flowfield solution. The effect of the canard on the elevon, measured using the elevon effectiveness ratio, decreased as the distance between the control surfaces increased. In general, higher Mach numbers combined with higher canard deflection angles resulted in a greater effect on the elevon. Adding a thickness correction, as opposed to assuming that the airfoils were flat plates, actually decreased, on average, the accuracy of the model when compared with the computational data.
\end{abstract}

\section{Nomenclature}

$\begin{array}{ll}a_{1}, a_{2}, & =\text { oblique shock equation constants } \\ a_{3} & \\ C_{1}, C_{2}, & =\text { series method isentropic constants } \\ C_{3} & =\text { airfoil chord length, } \mathrm{m} \\ c & =\text { series method nonisentropic constants } \\ D, E & =\text { resultant force on elevon, } \mathrm{N} \\ F & =\text { airfoil length, } \mathrm{m} \\ L & =\text { Mach number } \\ M & =\text { moment about center of gravity due to elevon, Nm } \\ M_{e} & =\text { pressure, Pa } \\ p & =\text { temperature, } \mathrm{K} \\ T & =\text { airfoil midchord thickness, } \mathrm{m} \\ t & =\text { horizontal distance, } \mathrm{m} \\ x & =\text { vertical distance, } \mathrm{m} \\ z & =\text { freestream angle of attack, deg } \\ \alpha & =\text { localized flow angle behind canard, deg } \\ \alpha^{\prime} & =\text { ratio of specific heats, } 1.4 \\ \gamma & =\text { distance between consecutive grid points, } \mathrm{m} \\ \Delta x & =\text { control surface deflection angle, deg } \\ \delta & =\text { flow turn angle, deg } \\ \delta_{f} & =\text { expansion fan ramp angle, deg } \\ \delta_{r} & =\text { shock angle, deg } \\ \theta_{s} & \end{array}$

Presented as Papers 6383 and 6384 at the 2008 AIAA Atmospheric Flight Mechanics Conference and Exhibit, Honolulu, HI, 18-21 August 2008; received 10 April 2009; revision received 29 August 2009; accepted for publication 19 September 2009. Copyright (C) 2009 by T. Skujins, C.E.S. Cesnik, M.W. Oppenheimer, and D.B. Doman. Published by the American Institute of Aeronautics and Astronautics, Inc., with permission. Copies of this paper may be made for personal or internal use, on condition that the copier pay the $\$ 10.00$ per-copy fee to the Copyright Clearance Center, Inc., 222 Rosewood Drive, Danvers, MA 01923; include the code 0022-4650/10 and $\$ 10.00$ in correspondence with the CCC.

*Graduate Research Assistant; tskujins@umich.edu. Member AIAA.

†rofessor, Department of Aerospace Engineering, 1320 Beal Avenue, 3024 Francois-Xavier Bagnoud Building; cesnik@umich.edu. Associate Fellow AIAA.

־Senior Electronics Engineer, Control Analysis and Design Branch; Michael.Oppenheimer@wpafb.af.mil. Senior Member AIAA.

${ }^{\S}$ Senior Aerospace Engineer, Control Analysis and Design Branch; David. Doman@wpafb.af.mil. Senior Member AIAA.

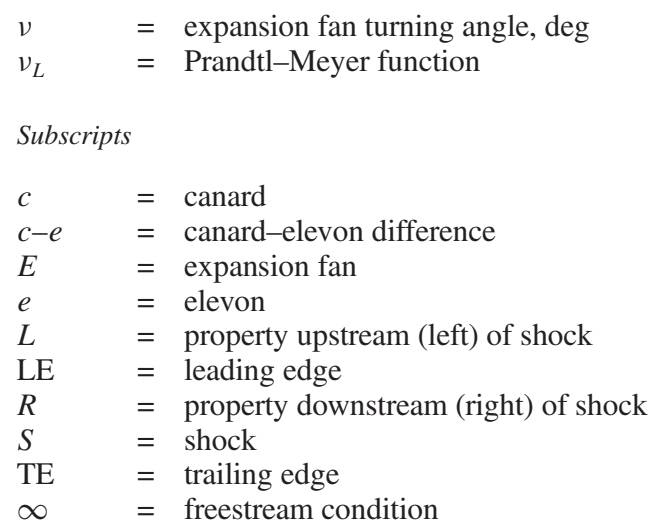

\section{Introduction}

MONG the major issues facing the development of airbreathing $A$ hypersonic cruise vehicles is that of maintaining controllability of the vehicle during the different phases of flight. Controller development for these vehicles is very challenging due to the coupling of various parameters affecting vehicle dynamics. The aerodynamics of the vehicle, airframe, propulsion system, and many other aspects all interact with each other and cannot be treated as separate issues. Because of these complicated interactions, computational hypersonic vehicle simulations are a vital tool used in vehicle research and development.

A specific area of importance with regard to vehicle dynamics is the airflow over the various control surfaces. Among different vehicle configurations, a tail-controlled vehicle augmented with a canard in the forebody has gained significant interest recently (e.g., Fig. 1). The canards serve two purposes. First, they give the vehicle the capability to increase pitching moment while cancelling changes in lift caused by deflection of the elevons. Second, they assist in low-speed handling. Hypersonic flow around these canards will result in changes in the flow propagating downstream, including shock waves, expansion fans, and a localized change in the freestream flow direction. It is vital to know how these phenomena will interact with the elevon control surfaces in the aftbody and impact their effectiveness. Not taking these effects into consideration can cause 


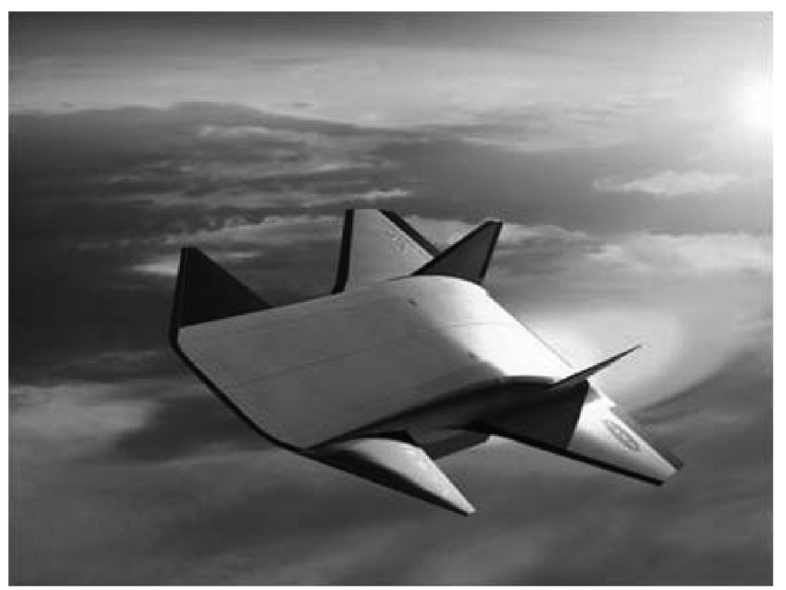

Fig. 1 NASA X-43B showing canard and elevon control surfaces.

misprediction of forces on the elevon that in turn results in potential lack of controllability of the vehicle.

Limited research has been performed on this problem. The two main studies of the flow conditions at the trailing edge of a twodimensional supersonic airfoil were presented by Kahane and Lees [1] and Lighthill [2]. Lighthill built upon the work of Busemann [3], who developed a power series method to determine the pressures behind shock waves and expansion fans, and used it to study the flow just behind a flat plate airfoil. Behind the trailing edge, the pressures of the flow from the top and bottom of the plate must be equal. Lighthill used Busemann's power series method to equate these pressures; as a result, the angle of the flow leaving the flat plate was calculated to be different than the original angle of attack. However, in his analysis, as pointed out by Kahane and Lees [1], he only considered the isentropic terms of the series.

The goal of this work is to analytically calculate the interaction effects between a canard and an elevon and compare the results with a computational solution. To do so first requires the calculation of the flow properties on the downstream surface, namely, the elevon. From a controls perspective, the objective is to determine the force and moment-generating capabilities of the elevon and, hence, the elevon effectiveness. The flow properties at the trailing edge of the canard are calculated using two techniques. The first uses Busemann's []ㅡ] series method, which, as will be seen, is accurate only for small flow turning angles. The second is a numerical technique developed in this work to balance the pressures on the top and bottom of the trailing edge of a flat plate. This provides a new flow turning angle, which, in general, is different than the leading-edge turning angle. Additionally, the flow just downstream of the trailing edge of the canard is assumed to be the incident flow on the elevon. A comparison between elevon effectiveness with and without the upstream effects is provided.

Next, the analytical results are compared with a computational fluid dynamics (CFD) Euler flowfield solution to determine the range of applicability of the analytical formulation. This comparison demonstrates several important factors. First, the range of validity of the analytical shock and expansion fan formulation is determined. Second, the CFD analysis shows whether or not the effects of the new flow turning angle will still be significant at the location of the elevon or if the flow has returned to its original angle. Third, the CFD analysis also shows if other interaction effects, such as shock and expansion fans from the canard directly impacting the elevon, play a larger role in affecting the elevon than the new flow turning angle. These other effects are certainly a significant part of the overall problem, but the scope of this research is limited to looking at the change in localized flow angle. Finally, in the CFD trials, the airfoils are modeled as thin diamond shapes, not flat plates. This work shows how accurate of an estimation it is for the numerical studies to consider the airfoils as flat plates. To investigate all of these factors, parametric studies are carried out by varying flight conditions, control surface angles, and several relative dimensions of the vehicle. For all of these studies, the elevon effectiveness (i.e., measure of the

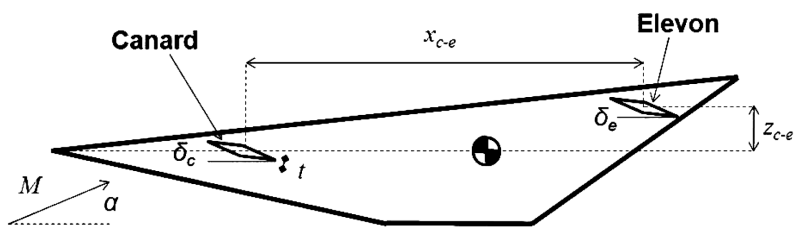

Fig. 2 Basic 2-D hypersonic vehicle configuration geometry.

change in the moment on the elevon per degree of change in elevon deflection) is used to quantify the canard's affect on the elevon.

Figure 2 shows the two-dimensional airbreathing hypersonic cruise vehicle considered in this work [4]. For the development of the analytical formulations, both the canard and elevon are modeled as flat plates hinged at their midpoints. However, for the computational trials, they are modeled as diamonds with the maximum thickness at the midchord location.

In characterizing the two-dimensional interaction effects here, a few assumptions are made. First, the effect of the bow shock from the front of the vehicle on the control surfaces is neglected. In reality, with the bow shock present, the incoming flow hitting the canard may be altered from freestream conditions based on the position of the bow shock. However, in this work the incoming flow is assumed to be freestream without loss of generality. Also, the flow properties at the elevon are the same as the flow properties at the trailing edge of the canard. In other words, no mixing between the canard flow and freestream flow occurs. This is the most extreme situation in the sense that the canard will have the maximum effect on the elevon. Additionally, the flow is assumed to be inviscid and the ratio of specific heats is a constant. Also, in the actual flowfield, many other effects are present and may become important. For example, the viscosity in the flow may prompt flow separation when the effective angle of attack becomes large. Preliminary studies conducted by the authors at Mach 8 and $85,000 \mathrm{ft}$ altitude suggested separation of the flow around a control surface when the equivalent angle of attack exceeds $12 \mathrm{deg}$ or so. However, these effects are not in the scope of this paper, which focuses on the investigation of the inviscid phenomenon of the localized change in flow angle behind the canard.

\section{Basic Two-Dimensional Flow Geometry and Calculations}

\section{A. Flow Behind the Canard}

Consider a supersonic flow over a flat plate with angle of attack $\alpha$ with respect to the flow and a canard deflection angle $\delta_{c}$, as shown in Fig. 3. When $\delta_{c}>-\alpha$, flow on the top side of the front of the plate will pass through a Prandtl-Meyer expansion fan, which will increase the Mach number while decreasing the pressure. The flow on the bottom will pass through an oblique shock, which decreases the Mach number and increases the pressure. At this point, the flow on both sides of the flat plate is parallel to the surface (canard). At the trailing edge, the streams are deflected so that they are again parallel to each other. The flow over the top will pass through an oblique shock while the flow on the bottom will pass through an expansion fan. The critical aspect here is that the flow direction downstream of the trailing edge is no longer parallel to the freestream flow. In fact, there is a surface of slip (or slipstream) between the flow coming from

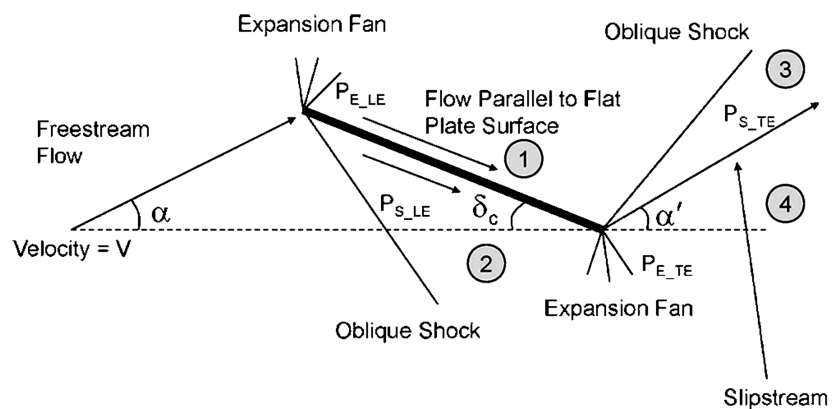

Fig. 3 Flow around canard. 
above and below the canard. The pressure in the regions above and below the slipstream are identical; however, the velocity, density, temperature, and entropy differ. One of the goals of this work is to determine the flow direction aft of the canard, relative to the body $x$ axis, denoted by $\alpha^{\prime}$.

At the trailing edge, the flow does not turn back parallel to the freestream but instead turns to a new angle, $\alpha^{\prime}$. The angle through which the flow turns at the rear of the flat plate self-adjusts to equalize the pressures above and below the slipstream.

\section{B. Analytical Calculation Methods}

The angle $\alpha^{\prime}$ was calculated using two different techniques. The first, referred to in this paper as the "numerical technique," uses an algorithm that solved the expansion and oblique shock equations for the angle $\left(\alpha^{\prime}\right)$ at which the flow pressures above and below the trailing edge of the canard are equal. The other, referred to as the "series solution," used a Taylor's series expansion $[2,3]$ relating the pressure change in the flow to the angle at which the flow turns. The goal was to determine how the numerical technique compared with the approximation of the series method, as well as determine the number of series terms necessary for agreement between the two methods over the ranges of $\alpha$ and $\delta_{c}$ tested. When calculating the effects of the canard on the elevon, it was assumed that the slipstream would continue at the angle $\alpha^{\prime}$ at which it left the trailing edge of the canard, neglecting any mixing with the freestream flow.

\section{Numerical Technique}

In the numerical technique, the flow properties behind an oblique shock or expansion fan are calculated numerically. For the oblique shock, the shock angle with respect to the freestream is a function of flow turn angle. The shock angle, $\theta_{s}$, can be found by solving the following polynomial for $\sin ^{2} \theta_{s}$ [5] :

$$
\sin ^{6} \theta_{s}+a_{1} \sin ^{4} \theta_{s}+a_{2} \sin ^{2} \theta_{s}+a_{3}=0
$$

where

$$
\begin{aligned}
& a_{1}=-\frac{M_{\infty}^{2}+2}{M_{\infty}^{2}}-\gamma \sin ^{2} \delta_{f} \\
& a_{2}=\frac{2 M_{\infty}^{2}+1}{M_{\infty}^{4}}+\left[\frac{(\gamma+1)^{2}}{4}+\frac{\gamma-1}{M_{\infty}^{2}}\right] \sin ^{2} \delta_{f} \\
& a_{3}=-\frac{\cos ^{2} \delta_{f}}{M_{\infty}^{4}}
\end{aligned}
$$

The weak shock solution is selected as the answer. Once the shock angle has been found, the flow properties can be determined using [ 5 ]

$$
\begin{aligned}
& \frac{p}{p_{\infty}}=\frac{7 M_{\infty}^{2} \sin ^{2} \theta_{s}-1}{6} \\
& \frac{T}{T_{\infty}}=\frac{\left(7 M_{\infty}^{2} \sin ^{2} \theta_{s}-1\right)\left(M_{\infty}^{2} \sin ^{2} \theta_{s}+5\right)}{36 M_{\infty}^{2} \sin ^{2} \theta_{s}} \\
& M^{2} \sin ^{2}\left(\theta_{s}-\delta\right)=\frac{M_{\infty}^{2} \sin ^{2} \theta_{s}+5}{7 M_{\infty}^{2} \sin ^{2} \theta_{s}-1}
\end{aligned}
$$

For flow over a convex corner, a Prandtl-Meyer expansion fan occurs. The first step here is to calculate the Prandtl-Meyer function, $v_{\infty}[\underline{6}]$ :

$$
v_{\infty}=\sqrt{\frac{\gamma+1}{\gamma-1}} \tan ^{-1} \sqrt{\frac{\gamma-1}{\gamma+1}\left(M_{\infty}^{2}-1\right)}-\tan ^{-1} \sqrt{M_{\infty}^{2}-1}
$$

The angle, $v$, through which the flow is turned is actually $v_{\infty}+\delta_{r}$, where $\delta_{r}$ is the expansion fan flow turn angle, which in reference to Fig. 3 equals $\alpha+\delta_{c}$ at the leading edge of the canard. To find the Mach number after the expansion, $M$, the following equation must be solved numerically:

$$
0=\sqrt{\frac{\gamma+1}{\gamma-1}} \tan ^{-1} \sqrt{\frac{\gamma-1}{\gamma+1}\left(M^{2}-1\right)}-\tan ^{-1} \sqrt{M^{2}-1}-v
$$

The remaining flow properties are calculated using isentropic flow relations []ㅜ:

$$
\frac{p}{p_{\infty}}=\left[\frac{1+\frac{\gamma-1}{2} M_{\infty}^{2}}{1+\frac{\gamma-1}{2} M^{2}}\right]^{\frac{\gamma}{\gamma-1}} \quad \frac{T}{T_{\infty}}=\left[\frac{1+\frac{\gamma-1}{2} M_{\infty}^{2}}{1+\frac{\gamma-1}{2} M^{2}}\right]
$$

Given the freestream flow properties, $\alpha$ and $\delta_{c}$, as inputs, the numerical technique calculates the flow properties on the top and bottom of the flat plate using the oblique shock and Prandtl-Meyer expansion fan equations discussed earlier. These calculations yield $p_{E_{\mathrm{LE}}}$ and $p_{S_{\mathrm{LE}}}$, along with the other flow properties in regions 1 and 2 of Fig. 3. At this point, the flow has been turned parallel to the flat plate. The same oblique shock and expansion fan expressions are then used to determine the properties of the flow at the trailing edge of the canard in regions 3 and 4 of Fig. 3 . The objective is to find the trailing-edge wedge angle, $\alpha^{\prime}$, that yields equivalent upper and lower pressures at the trailing edge of the canard $\left(p_{E_{\mathrm{TE}}}=p_{S_{\mathrm{TE}}}\right)$. This algorithm then iterates on this angle until the pressures are equal. The starting guess is taken to be the wedge angle $\alpha+\delta_{c}$. The outputs of the algorithm are the properties of the flow in regions 1,2,3, and 4 of Fig. 3 , along with the angle $\alpha^{\prime}$.

\section{Series Solution}

Busemann [3] devised a method to find the turning angle of a flow passing through an expansion or an oblique shock using a Taylor series expansion, relating the pressure change to the turning angle of the flow $\delta_{f}$. Busemann's expression for the change in pressure is

$$
\begin{aligned}
& \frac{p-p_{\infty}}{\frac{1}{2} \gamma p_{\infty} M_{\infty}^{2}}= \pm C_{1}\left(\delta_{f}\right)+C_{2}\left(\delta_{f}\right)^{2} \pm\left(C_{3}-D\right)\left(\delta_{f}\right)^{3} \\
& \quad+\left(C_{4}-E\right)\left(\delta_{f}\right)^{4}
\end{aligned}
$$

where

$$
\begin{gathered}
C_{1}=\frac{2}{\sqrt{M_{\infty}^{2}-1}} \\
C_{2}=\frac{\left(M_{\infty}^{2}-2\right)^{2}+\gamma M_{\infty}^{4}}{2\left(M_{\infty}^{2}-1\right)^{2}} \\
C_{3}=\frac{M_{\infty}^{4}}{\left(M_{\infty}^{2}-1\right)^{\frac{7}{2}}}\left[\frac{\gamma+1}{6}\left(M_{\infty}^{2}-\frac{5+7 \gamma-2 \gamma^{2}}{2(\gamma+1)}\right)^{2}+\frac{-4 \gamma^{4}+28 \gamma^{3}+11 \gamma^{2}-8 \gamma-3}{24(\gamma+1)}\right]+\frac{3\left(M_{\infty}^{2}-\frac{4}{3}\right)^{2}}{4\left(M_{\infty}^{2}-1\right)^{\frac{7}{2}}} \\
D=\frac{\gamma+1}{12} \frac{M_{\infty}^{4}}{\left(M_{\infty}^{2}-1\right)^{\frac{7}{2}}}\left[\frac{(5-3 \gamma)}{4}\left(M_{\infty}^{2}-\frac{6-2 \gamma}{5-3 \gamma}\right)^{2}-\frac{\gamma^{2}-1}{5-3 \gamma}\right] \\
C_{4}-E=\frac{\frac{3 \gamma^{3}-3 \gamma^{2}-7 \gamma-1}{24} M_{\infty}^{10}+\frac{3 \gamma^{3}-3 \gamma^{2}+33 \gamma+7}{24} M_{\infty}^{8}+\frac{3 \gamma^{2}-9 \gamma-2}{3} M_{\infty}^{6}+\frac{8 \gamma+2}{3} M_{\infty}^{4}-\frac{2}{3} M_{\infty}^{2}+\frac{2}{3}}{\left(M_{\infty}^{2}-1\right)^{5}}
\end{gathered}
$$


The quantity $C_{4}-E$ was given in Hilton [7] as well as the method for the derivation of $C_{4}$ by itself.

Initially, the flow is freestream, inclined at an angle $\alpha$ with respect to the horizontal (see Fig. 3 ). The turning angle for the leading edge of the flat plate is therefore $\delta_{\mathrm{LE}}=\alpha+\delta_{c}$. For the trailing edge, the flow turning angle is $\delta_{\mathrm{TE}}=\alpha^{\prime}+\delta_{c}$. The constants $D$ and $E$ are used only in the case of an oblique shock, which is nonisentropic. $D$ and $E$ are not included for the expansion fan calculations. The constants $C_{1}$, $C_{2}, C_{3}$, and $C_{4}$ assume isentropic flow, such as is found in a PrandtlMeyer expansion. However, the nonisentropic losses become significant once the third-order term is reached, and so it is necessary to include the constants $D$ and $E$ on the higher-order terms for the oblique shock case. Also, the upper sign in Eq. (7) is used on the upper surface, while the lower sign in Eq. (7) is used on the lower surface.

The pressures on the top and bottom of the canard are determined using this series with the known freestream properties and wedge angles. To find the turning angle at the rear of the flat plate, the expressions for the pressures above and below the slipstream behind the trailing edge were subtracted from each other and iterations on $\alpha^{\prime}$ were performed until these pressures were equal.

\section{Method Comparison}

Both of the methods were used to find $\alpha^{\prime}$ for cases with $\delta_{c}$ ranging from -20 to $+20 \mathrm{deg}$ and $\alpha$ ranging from -1 to $5 \mathrm{deg}$. For the series method, different orders of approximations were used, ranging from first to fourth. The different order series, referring to Eq. (7), are defined as

$$
\begin{aligned}
& \text { first order: } \frac{p-p_{\infty}}{\frac{1}{2} \gamma p_{\infty} M_{\infty}^{2}}= \pm C_{1}\left(\delta_{f}\right) \\
& \text { second order: } \frac{p-p_{\infty}}{\frac{1}{2} \gamma p_{\infty} M_{\infty}^{2}}= \pm C_{1}\left(\delta_{f}\right)+C_{2}\left(\delta_{f}\right)^{2} \\
& \text { third order: } \frac{p-p_{\infty}}{\frac{1}{2} \gamma p_{\infty} M_{\infty}^{2}}= \pm C_{1}\left(\delta_{f}\right)+C_{2}\left(\delta_{f}\right)^{2} \pm\left(C_{3}-D\right)\left(\delta_{f}\right)^{3} \text {, } \\
& \text { fourth order: } \frac{p-p_{\infty}}{\frac{1}{2} \gamma p_{\infty} M_{\infty}^{2}}= \pm C_{1}\left(\delta_{f}\right)+C_{2}\left(\delta_{f}\right)^{2} \\
& \qquad \pm\left(C_{3}-D\right)\left(\delta_{f}\right)^{3}+\left(C_{4}-E\right)\left(\delta_{f}\right)^{4}
\end{aligned}
$$

Figures 4-7 show the values of $\alpha^{\prime}$ versus $\delta_{c}$ for the first- through fourth-order series methods. The solid lines in these figures correspond to the $\alpha^{\prime}$ values calculated with the numerical technique, while the dashed lines correspond to $\alpha^{\prime}$ values calculated with the series method. Clearly, the first-order method poorly estimates $\alpha^{\prime}$ for wedge angles larger than about 3 deg (see Fig. 4). Likewise, the second-order method is only accurate for wedge angles of about $5 \mathrm{deg}$. The third-order series method (Fig. 6) produced acceptable results for $\alpha^{\prime}$ for wedge angles up to around $\overline{7} \mathrm{deg}$. The fourth-order series method is quite accurate up to about $13 \mathrm{deg}$.

The issue with the differences between $\alpha^{\prime}$ computed with the two techniques is simply the difference in calculations of pressures behind a shock or expansion for the two methods. As the order of the series increases, the calculation of surface pressures more closely matches the results from numerically solving the oblique shock/ expansion fan equations. Figure 8 shows the pressure on the lower surface of the canard as computed using the first- and fourth-order series method expansion fan/shock calculations and the expansion fan/shock relationships in Eqs. (4-6) and Eqs. (1-3). Figure 9 shows the results for the upper surface of the canard. Again, the first-order series method poorly computes the pressures behind the expansion fan and shock. Increasing the order of the series can yield significant improvements, as the fourth-order series method more closely resembles the numerical calculations. The differences in $\alpha^{\prime}$ between the series and numerical methods is a direct result of the pressures being calculated differently. These errors get magnified by the fact that, as the flow is turned through an expansion and shock at the rear of the canard, these series calculations are performed again. Figure 10 shows the pressures below and above the slipstream behind the canard as computed using the first-order series method and the

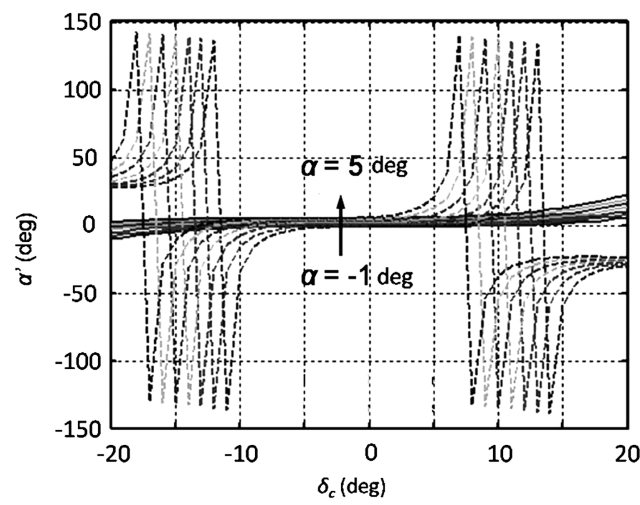

Fig. $4 \alpha^{\prime}$ for numerical technique (solid lines) and first-order series method (dashed lines).

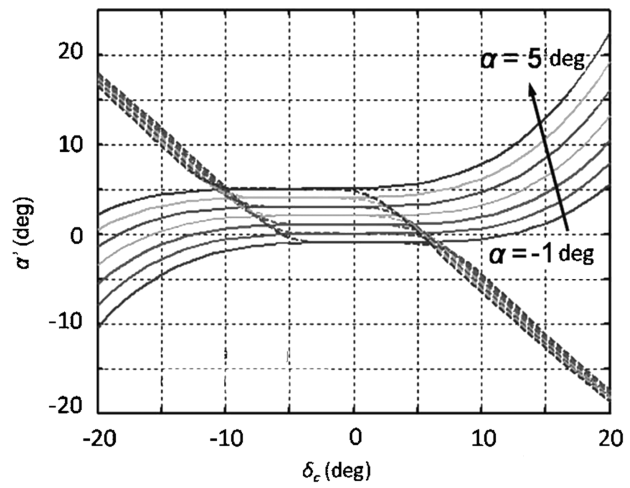

Fig. $5 \alpha^{\prime}$ for numerical technique (solid lines) and second-order series method (dashed lines).

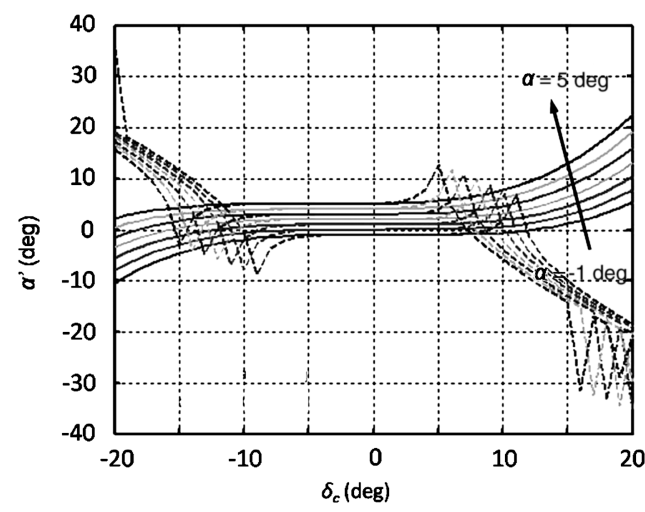

Fig. $6 \alpha^{\prime}$ for numerical technique (solid lines) and third-order series method (dashed lines).

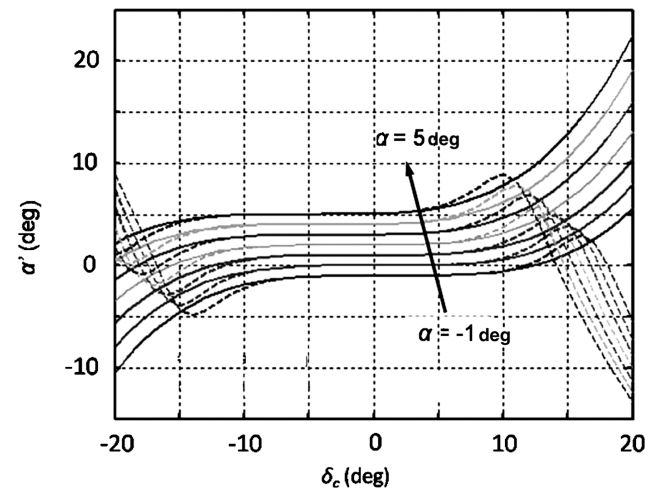

Fig. $7 \quad \alpha^{\prime}$ for numerical technique (solid lines) and fourth-order series method (dashed lines). 


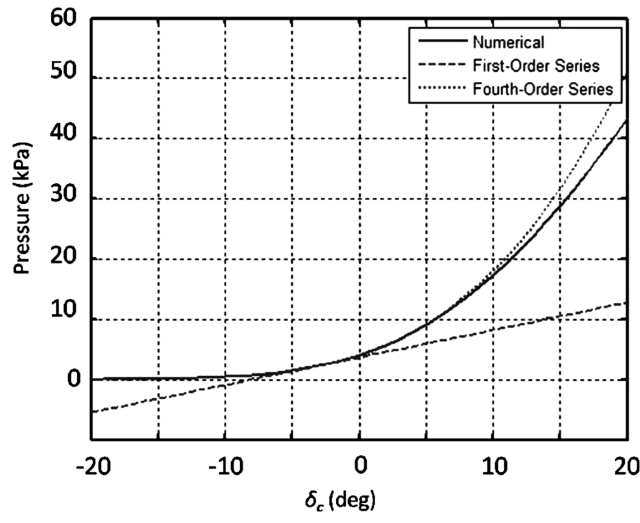

Fig. 8 Pressure on lower surface of canard.

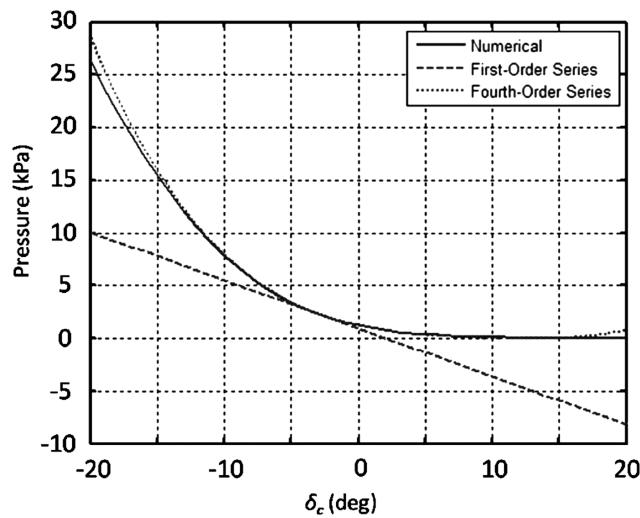

Fig. 9 Pressure on upper surface of canard.

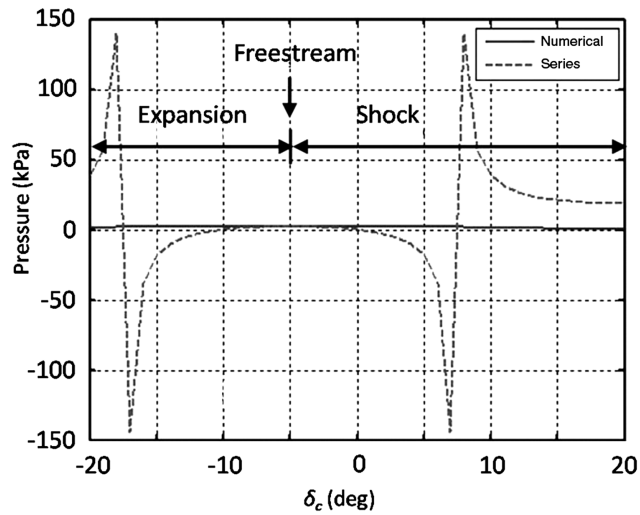

Fig. 10 Pressure below and above slipstream: numerical and firstorder series.

numerical technique. The errors in the calculation at the leading edge of the canard have propagated and the pressures, as computed by the two methods, are much different. When computing $\alpha^{\prime}$, the pressures below and above the slipstream are equated. Because the pressures calculated using the series method and those calculated using the numerical technique differ, the $\alpha^{\prime}$ values differ. Similar results occur when the fourth-order series method is used, as shown in Fig. 11. As was the case with the leading edge, the fourth-order series method is more accurate than the first-order series method, but differences do exist when compared to the numerical calculations.

\section{Elevon Control Surface}

This slipstream effect must be taken into account to determine the flow on the elevon control surface. The geometry of the interaction is shown in Fig. 12, in which $\alpha_{\max }^{\prime}$ and $\alpha_{\min }^{\prime}$ are the maximum and minimum angles, measured from the horizontal, at which the

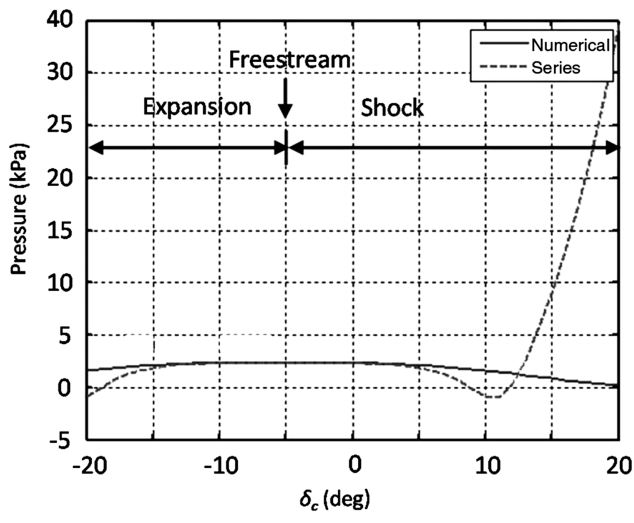

Fig. 11 Pressure below and above slipstream: numerical and fourthorder series.

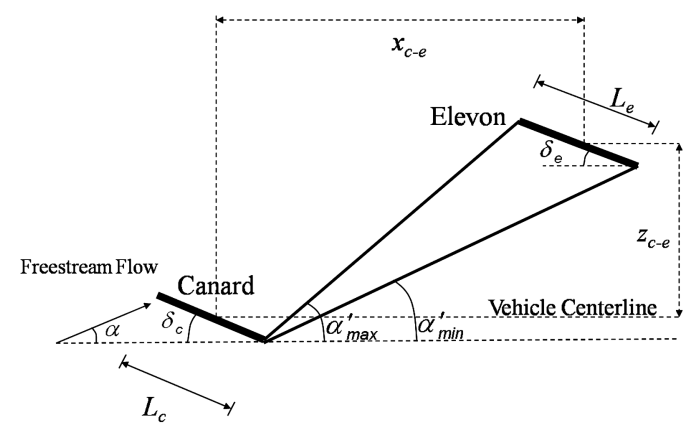

Fig. 12 Canard-elevon interactions.

slipstream can come off the canard and strike the elevon. They can be expressed in terms of the other vehicle dimensions with the following equations:

$$
\begin{aligned}
& \alpha_{\max }^{\prime}=\arctan \left[\frac{z_{c-e}+\frac{1}{2} L_{c} \sin \delta_{c}+\frac{1}{2} L_{e} \sin \delta_{e}}{x_{c-e}-\frac{1}{2} L_{c} \cos \delta_{c}-\frac{1}{2} L_{e} \cos \delta_{e}}\right] \\
& \alpha_{\text {min }}^{\prime}=\arctan \left[\frac{z_{c-e}+\frac{1}{2} L_{c} \sin \delta_{c}-\frac{1}{2} L_{e} \sin \delta_{e}}{x_{c-e}-\frac{1}{2} L_{c} \cos \delta_{c}+\frac{1}{2} L_{e} \cos \delta_{e}}\right]
\end{aligned}
$$

Recall that it is assumed that the flow seen by the elevon is the flow leaving the trailing edge of the canard. Hence, no mixing of the flow, at the trailing edge of the canard, with freestream flow occurs.

Figure 13 shows the geometry of the flow incident upon the elevon. When $\alpha^{\prime}>\alpha_{\max }^{\prime}$, the flow incident upon the elevon is the flow below the slipstream at the trailing edge of the canard. When $\alpha^{\prime}<\alpha_{\min }^{\prime}$, the flow incident upon the elevon is the flow above the slipstream at the trailing edge of the canard. When $\alpha_{\min }^{\prime} \leq \alpha^{\prime} \leq \alpha_{\max }^{\prime}$, the slipstream impinges upon the elevon. In this case, if $\delta_{e}>-\alpha^{\prime}$, the elevon experiences the flow above the slipstream. On the other hand, if $\delta_{e}<-\alpha^{\prime}$, the elevon experiences the flow below the slipstream. The algorithm to determine the flow properties on the elevon is as follows:

1) If $\alpha^{\prime}>\alpha_{\max }^{\prime} \Rightarrow$ incident flow on elevon $=$ flow below slipstream

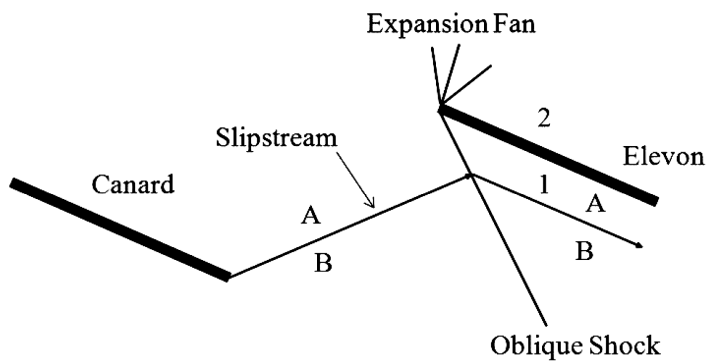

Fig. 13 Slipstream incident on elevon. 
2) If $\quad \alpha^{\prime}<\alpha_{\min }^{\prime} \Rightarrow$ incident flow on elevon = flow above slipstream

3) If $\quad \alpha_{\min }^{\prime} \leq \alpha^{\prime} \leq \alpha_{\max }^{\prime} \Rightarrow$ check additional condition. If $\delta_{e}>-\alpha^{\prime} \Rightarrow$ incident flow on elevon $=$ flow above slipstream, if $\delta_{e}<-\alpha^{\prime} \Rightarrow$ incident flow on elevon $=$ flow below slipstream

Oblique shock and expansion fan computations are used, with the initial flow properties discussed earlier, to compute the flow properties on the top and bottom surfaces of the elevon. The ultimate goal is to determine how the flow leaving the canard affects the elevon. In Sec. III, the elevon effectiveness is calculated.

\section{Elevon Effectiveness}

Now that the flow properties at the elevon have been calculated, the effectiveness of the elevon can be determined. To begin, the static pressures on the top and bottom of the elevon are integrated to determine the forces due to this control surface. Because the elevon is primarily used for attitude control, the pitching moment due to these forces is calculated. Recall that the goal is to determine the effects of the upstream canard control surface on the moment-generating effectiveness of the elevon. Figure 14 shows the moment ratio produced by the elevon when the canard flow is incident upon the elevon for two different angles of attack ( $\alpha=-1$ and $5 \mathrm{deg}$ ). The moment ratio is defined as the moment generated by the elevon due to the disturbed flow from the canard divided by the moment the elevon would generate if the elevon experienced freestream flow. It should be pointed out that, if freestream flow impinges the elevon, the moment produced is independent of canard deflection. Clearly, as the effective wedge angle of the canard increases, the moment produced by the elevon decreases when compared to the one it would generate with freestream conditions. Hence, the elevon becomes less effective as the flow turn angle for the upstream control effector increases. In Fig. 14, the sharp change in moment from $\delta_{c}=-19$ to -18 deg is due to the incident flow on the elevon changing from flow above the slipstream when $\alpha=5 \mathrm{deg}, \delta_{c}=-19 \mathrm{deg}$, and $\delta_{e}=8 \mathrm{deg}$ to flow below the slipstream when $\alpha=5 \mathrm{deg}, \delta_{c}=-18 \mathrm{deg}$, and $\delta_{e}=8 \mathrm{deg}$. This result shows that when the effects of the canard are taken into account on the elevon, a significant decrease in moment produced by the elevon can result. These effects are directly seen in terms of elevon effectiveness. The elevon effectiveness is defined as the change in moment produced by the elevon per change in elevon deflection, that is,

$$
\frac{\mathrm{d} M_{e}}{\mathrm{~d} \delta_{e}}=\frac{M_{e}\left(M, \alpha, \delta_{c}, \delta_{e_{i}}\right)-M_{e}\left(M, \alpha, \delta_{c}, \delta_{e_{i-1}}\right)}{\delta_{e_{i}}-\delta_{e_{i-1}}}
$$

Thus, the elevon effectiveness is computed using a finite difference. This result can be normalized by the control effectiveness of the elevon if it were subjected to freestream flow conditions (and, therefore, independent of canard deflection), such that

$$
\text { elevon effectiveness ratio }=\frac{\frac{\partial M_{e}}{\partial \delta_{e}}}{\left.\frac{\partial M_{e}}{\partial \delta_{e}}\right|_{\infty}}
$$

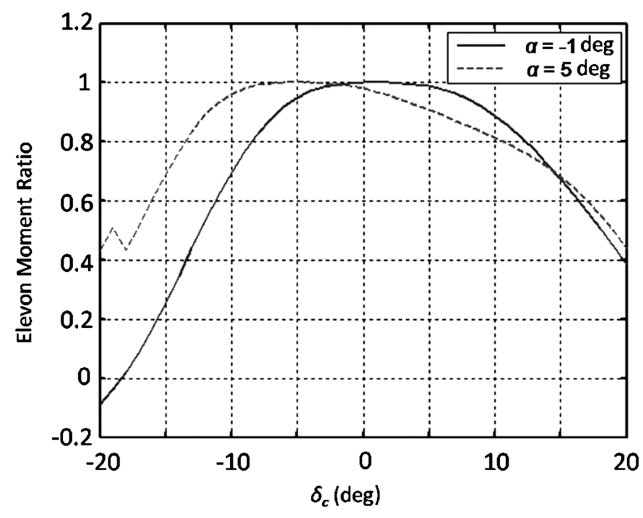

Fig. 14 Elevon moment ratio: elevon deflection $=8 \mathrm{deg}$.

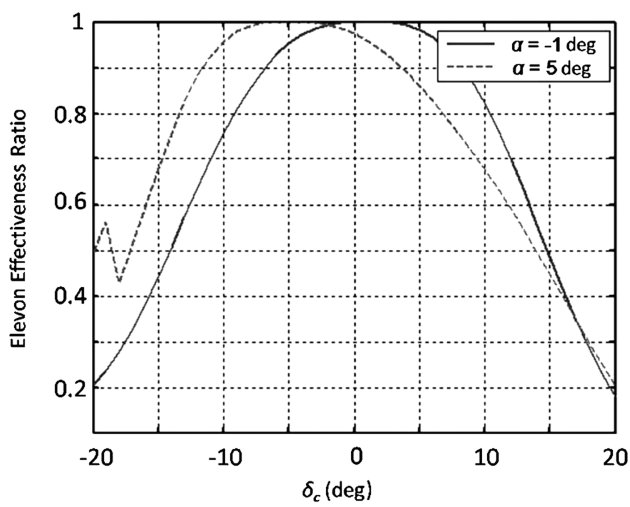

Fig. 15 Elevon effectiveness ratio: elevon deflection $=8 \mathrm{deg}$.

Figure 15 shows the elevon effectiveness ratio for $\delta_{e}=8 \mathrm{deg}$ and angles of attack of -1 and $5 \mathrm{deg}$. As expected, for large canard wedge angles, the effectiveness of the elevon decreases significantly when the flow from the canard is incident upon the elevon, as compared to assuming freestream flow incident upon the elevon.

\section{Computational Fluid Dynamics Analysis}

The results of the numerical calculation were used for comparison with CFD results, as these were shown to be applicable for a larger range of wedge angles than the series approximation. For this computational analysis, the CFD package CFD++ Version 7.1.1, from Metacomp Technologies, was used [8] . The geometries were constructed using the grid generator Gridgen Version 15.11 from Pointwise, Inc. [9]. Unstructured meshes were created for each trial run and imported into CFD++. Depending on the trial run, between 250 and 300 grid points were placed on each airfoil surface; they were clustered closer together at the ends of the faces to capture the shock and expansion fan effects most accurately. Also, in hypersonic flow, the shocks and expansions are located near to the canard and elevon surfaces. Because of this, it was necessary to create layers of points near the surfaces similar to boundary-layer points. Grid studies showed that these layers were necessary to best resolve the large gradients in the flowfield properties that occur near the surfaces. The clustering of points near the airfoil edges served to resolve the shocks and expansions in the longitudinal direction down the airfoil, while the layers served to resolve them outward from the airfoil surface (see Fig. 17). The mesh was also fine in the region between the canard and elevon, as that is the flow region of interest in this study. Figure 16 shows an example mesh with the canard and elevon, while Fig. 17 shows a close-up of the elevon.

In CFD++, Euler solutions were obtained by first starting the runs out with a first-order solver. Then, the solver gradually switched to second order for the remainder of the run, as recommended in the CFD++ documentation [8]. Anywhere from 750 to 1200 iterations were completed for the trials, which were stopped when the residuals reached a constant value. The air was modeled as a perfect gas.

Before beginning with the actual trial runs, validation cases were conducted for the grid. As an example, Fig. 18 shows the pressures on each face of a diamond airfoil obtained from the analytical

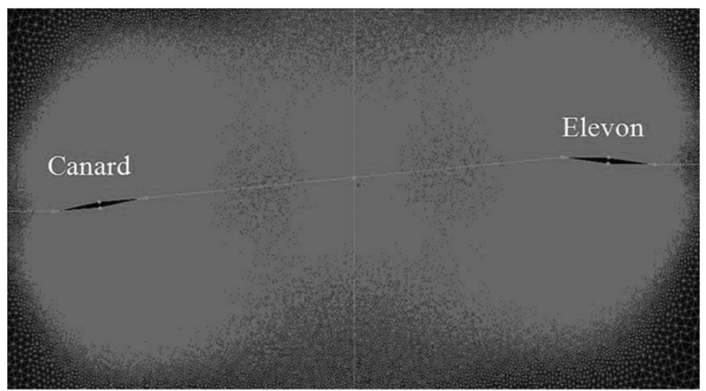

Fig. 16 CFD trial run example mesh. 


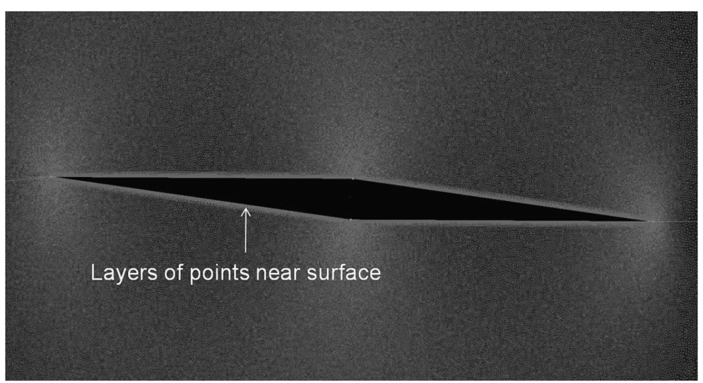

Fig. 17 Mesh around elevon.

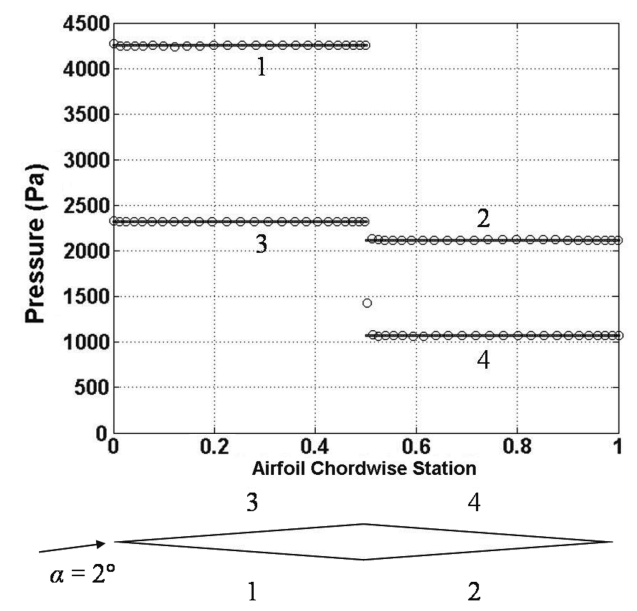

Fig. 18 Face pressures for an isolated diamond-shaped airfoil (circles: CFD results, line: analytical formulation).

shock/expansion formulation and CFD++. Note that this is a single airfoil without any interference in front of it. Table 1 summarizes the various parameters for this run. As can be seen, the pressures obtained using $\mathrm{CFD}++$ match well with the pressures predicted using the analytical shock/expansion fan formulation, with the two results falling on top of each other. The symbols along the geometric transition points, that is, the leading edge, midchord location, and trailing edge, represent the finite pressure transitions that exist in these regions. Note that, due to the high number of grid points on each airfoil face, the CFD squares are clustered close together and, therefore, appear to be a solid line.

\section{Parametric Studies}

Parametric studies were conducted to evaluate the range of validity of the analytical shock and expansion fan formulation in determining the elevon control effectiveness. Refer to Fig. 2 for the parametrization of the 2-D hypersonic model. Table 2 summarizes the range of interest for the parameters that will be investigated.

\section{A. Latin Hypercube Sampling}

To most efficiently span the parameter space, defined in Table 2 , with the CFD trial runs, nearly orthogonal Latin hypercube sampling was used. For this study, it would have proved infeasible to run a trial with each parameter value paired with all the other parameters' values. For example, if only four separate values of each of the seven parameters were considered, the resulting test matrix would have consisted of $4^{7}=16,384$ trial runs. The computational cost of running that many trial runs is prohibitively high.

Table 1 Validation case parameters

\begin{tabular}{lccc}
\hline \hline$M$ & $\alpha$ & Airfoil deflection & Midchord thickness \\
\hline 6.50 & $2.00 \mathrm{deg}$ & $0.00 \mathrm{deg}$ & $0.040 c$ \\
\hline \hline
\end{tabular}

Nearly orthogonal Latin hypercubes provide a method of spanning the entire parameter space with a relatively small amount of trial runs [10]. An important characteristic of an orthogonal matrix is that data in any column may not have a linear relationship with the data in any other column. In creating an orthogonal matrix, each of the parameters are divided into the desired number of values, which are evenly spaced throughout the specific parameter's range; the parameter values are then placed in a column. Then, the values of each parameter are paired with the values for the other parameters, taking care not to allow any type of linear relationship between columns. In a nearly orthogonal Latin hypercube matrix, an extremely weak linear relationship between columns is permitted out of necessity. For a parameter space consisting of seven parameters, the ideal number of trials for a nearly orthogonal test matrix is 17 [11]. To create the test matrix for this study, the spreadsheet created by SanchezI was obtained. By inputting the parameters and the ranges of the parameters, the optimal space-filling nearly orthogonal Latin hypercube test matrix was automatically created. This matrix is shown in Table 3 .

\section{B. Slipstream Tests}

In addition to the Latin hypercube test matrix, a flight condition for which the analytical shock and expansion fan formulation predicted the slipstream to strike the elevon was investigated. The analytical formulation assumes that the slipstream will continue back behind the canard indefinitely. To test how accurate this assertion is, the elevon was moved from a range of 3-15 chord lengths (horizontally) behind the canard while adjusting the vertical canard-elevon distance such that the slipstream would strike the elevon at a consistent location. Table 4 summarizes the values held constant and used on all of the slipstream tests. Table $\underline{5}$ summarizes the horizontal and vertical canard-elevon distances for the trials, which were the only parameters altered on any of the slipstream tests.

\section{Analysis Procedure}

For each of the trial runs conducted, the elevon effectiveness ratio was calculated. Because the ratio is found using a finite difference method, as discussed earlier, four separate CFD tests were conducted for each trial run; they are summarized in Table 6 .

The resultant forces on the elevon in the CFD trials were found by numerically integrating the pressures on the airfoil. To eliminate effects due to numerics at the leading and trailing edges of the airfoil faces, the pressures from 10 to $90 \%$ of the airfoil face length were used. Once the pressures were obtained, the resultant force $F$ on the face was found by using a trapezoidal rule numerical integration scheme, that is,

$$
F=\sum \frac{1}{2}[p(x+\Delta x)+p(x)] \Delta x
$$

The resultant forces on the airfoil faces were broken down into horizontal and vertical components. Then, the total horizontal and vertical forces on the elevon were found by summing the components of the forces on each face. Next, the moment due to the elevon about the vehicle's center of gravity was calculated, assuming that the center of gravity is located $\frac{4}{7}$ of the way horizontally from the canard to the elevon down the body axis, as shown in Fig. 19, that is,

$$
\frac{x_{c}}{x_{c}+x_{e}}=\frac{4}{7}
$$

Vertically, the center of gravity is in line with the canard. These dimensions are exactly the same as the ones used by Oppenheimer et al. [4] and serve to standardize the moment calculations by making the ratio of the elevon $x$-moment arm and $x_{c-e}$ constant. Finally, the finite difference method discussed earlier was used to calculate the elevon effectiveness ratio for each trial run.

"Data on S.M. Sanchez, "NOHL designs spreadsheet," 2005 available online at http://diana.cs.nps.mil/SeedLab [retrieved 27 June 2008]. 
Table 2 Parametric ranges of interest

\begin{tabular}{lcc}
\hline \hline Parameter & Minimum & Maximum \\
\hline$M$ & 3.00 & 10.0 \\
$\alpha$ & $-1.00 \mathrm{deg}$ & $5.00 \mathrm{deg}$ \\
$\delta_{c}$ & $-12.0 \mathrm{deg}$ & $12.0 \mathrm{deg}$ \\
$\delta_{e}$ & $-15.0 \mathrm{deg}$ & $15.0 \mathrm{deg}$ \\
$t$ & 0.00 & $0.08 c$ \\
$x_{c-e}$ & $5 c$ & $12 c$ \\
$z_{c-e}$ & $0.15 c$ & $0.75 c$ \\
\hline \hline
\end{tabular}

Table 3 Test matrix

\begin{tabular}{lccccccc}
\hline \hline Trial & $M$ & $\alpha$ & $\delta_{c}$ & \multicolumn{1}{c}{$\delta_{e}$} & $t$ & $x_{c-e}$ & $z_{c-e}$ \\
\hline 1 & 5.19 & 5.00 & 7.50 & -3.75 & $0.020 c$ & $11.6 c$ & $0.488 c$ \\
2 & 3.44 & 0.50 & 9.00 & 1.88 & $0.000 c$ & $7.19 c$ & $0.525 c$ \\
3 & 3.88 & 1.62 & -10.5 & -7.50 & $0.050 c$ & $10.7 c$ & $0.750 c$ \\
4 & 4.31 & 2.75 & -4.50 & 15.0 & $0.045 c$ & $5.88 c$ & $0.600 c$ \\
5 & 8.25 & 4.62 & -1.50 & -11.2 & $0.025 c$ & $5.00 c$ & $0.638 c$ \\
6 & 10.0 & 0.88 & -3.00 & 9.38 & $0.005 c$ & $10.2 c$ & $0.675 c$ \\
7 & 7.38 & 0.12 & 12.0 & -5.62 & $0.070 c$ & $8.06 c$ & $0.712 c$ \\
8 & 6.94 & 4.25 & 6.00 & 13.1 & $0.065 c$ & $9.38 c$ & $0.562 c$ \\
9 & 6.50 & 2.00 & 0.00 & 0.00 & $0.040 c$ & $8.50 c$ & $0.450 c$ \\
10 & 7.81 & -1.00 & -7.50 & 3.75 & $0.060 c$ & $5.44 c$ & $0.412 c$ \\
11 & 9.56 & 3.50 & -9.00 & -1.88 & $0.080 c$ & $9.81 c$ & $0.375 c$ \\
12 & 9.12 & 2.38 & 10.5 & 7.50 & $0.030 c$ & $6.31 c$ & $0.150 c$ \\
13 & 8.69 & 1.25 & 4.50 & -15.0 & $0.035 c$ & $11.1 c$ & $0.300 c$ \\
14 & 4.75 & -0.62 & 1.50 & 11.2 & $0.055 c$ & $12.0 c$ & $0.262 c$ \\
15 & 3.00 & 3.12 & 3.00 & -9.38 & $0.075 c$ & $6.75 c$ & $0.228 c$ \\
16 & 5.62 & 3.88 & -12.0 & 5.62 & $0.010 c$ & $8.94 c$ & $0.188 c$ \\
17 & 6.06 & -0.25 & -6.00 & -13.1 & $0.015 c$ & $7.62 c$ & $0.338 c$ \\
\hline \hline
\end{tabular}

\section{Results and Discussion}

\section{A. Slipstream Observations}

Before the elevon effectiveness ratio results are obtained from the trials, it is necessary to study the existence of the slipstream itself. Figures 20-22 show the Mach contours of the trials described in Tables $4 \overline{\text { and }} \overline{5}$ with canard-elevon separations of 3.00, 7.00, and 12.0 chord lengths, respectively.

The slipstream can be seen in Figs. 21 and 22, as indicated by the solid line, which is very near to the superimposed dashed line showing the location of the slipstream as calculated by the analytical formulation. It appears that, as the slipstream travels farther downstream, it is affected by flow with values closer to that of the freestream. As it does so, the slipstream appears to gradually change directions and move at an angle closer to the freestream $\alpha$, as shown in Fig. 22. Also, as the perpendicular distance away from the slipstream is increased, the flow conditions become closer to the precanard freestream values than the values predicted by the analytical formulation for above and below the slipstream.

\section{B. Latin Hypercube Test Matrix}

Table 7 summarizes the elevon effectiveness ratio results calculated for the trials defined by the Latin hypercube test matrix. Note that two separate analytical shock/expansion fan calculations were used. The first, labeled "analytical, thick" in the table, included the thickness effects of the diamond airfoil. The second, labeled "analytical, flat" in the table, assumed that all of the airfoils were flat plates. The percent error columns refer to the differences between the respective analytical formulation and the CFD results. Also, note that the mean percent error and the standard deviation at the bottom of Table 7 are with respect to error values from each column.
Table 5 Slipstream trial run variables

\begin{tabular}{lcc}
\hline \hline Trial & $x_{c-e}$ & $z_{c-e}$ \\
\hline $1 \mathrm{~s}$ & $3 c$ & $0.075 c$ \\
$2 \mathrm{~s}$ & $5 c$ & $0.213 c$ \\
$3 \mathrm{~s}$ & $7 c$ & $0.350 c$ \\
$4 \mathrm{~s}$ & $9 c$ & $0.488 c$ \\
$5 \mathrm{~s}$ & $12 c$ & $0.695 c$ \\
$6 \mathrm{~s}$ & $15 c$ & $0.902 c$ \\
\hline \hline
\end{tabular}

Table 6 CFD test conditions to evaluate the elevon effectiveness ratio

\begin{tabular}{lcl}
\hline \hline Test & Canard present & \\
\hline 1 & Yes & As specified by test matrix \\
2 & Yes & 1 deg less than specified by test matrix \\
3 & No & As specified by test matrix \\
4 & No & 1 deg less than specified by test matrix \\
\hline \hline
\end{tabular}

The results in Table 7 show that the analytical shock and expansion fan formulation assuming a flat plate agrees more closely on average with the CFD test results than the formulation taking thickness into consideration. There are several cases in which the thickness corrections improve the correlations with CFD. However, in those cases, the error is already small, typically less than $3 \%$. For example, trial 5 shows that including the thickness of the airfoil reduces the error from -1.90 to $0.26 \%$. On the other hand, the analytical formulation with thickness for trial 11 , which with a midchord thickness of $8.00 \%$ is the thickest one considered, differs from the CFD results by $37.9 \%$ while the flat plate formulation differs by only $5.59 \%$. For this case, the thickness formulation predicts a Mach number of 8.90 above the slipstream and 7.57 below the slipstream, compared with a freestream value of 9.56 . Figure 23 shows the Mach number contours of this trial case. Figure 24 shows an expanded view of box A in Fig. 23.

Around location 1 in Fig. 24, the Mach numbers on each side of the slipstream, marked in the figure, match fairly well with those predicted by the thickness formulation. However, by the time the flow has reached location 2, the Mach numbers, while not completely back to freestream values, have increased, displayed by the fact that the darker shades very close to the $\alpha$ line have gone away. This shows that the lower Mach numbers predicted by the thickness formulation behind the trailing edge of the airfoil are relatively local effects, dissipating with distance. Though the slipstream and, hence, the slightly lower Mach numbers continue back to the area around the elevon, the Mach numbers are higher than predicted by the thickness formulation. Also, away from the slipstream, the Mach numbers increase with distance due to freestream interactions. The analytical formulation assumes that the flow conditions directly above and below the slipstream at the trailing edge continue both backward and away from the slipstream. As shown in the contour plots, the thickness effects do not extend very far behind the airfoil. The flat plate formulation does not predict as extreme of a Mach number change behind the canard, returning Mach numbers above and below the slipstream of 9.38 and 9.21, respectively, for trial 11. As such, the flat plate formulation in many cases was proven to be the more accurate model.

Two trial runs (not including trial 7, which was impacted by the canard's shock/expansion fan system) had significantly lower elevon effectiveness ratios: trial $8(0.762)$ and trial $12(0.728)$; the next lowest was trial 13 (0.874). Trials 8 and 12 had relatively large Mach number/canard wedge angle $\left(\alpha+\delta_{c}\right)$ combinations, 6.94/10.2 deg and 9.12/12.9 deg, respectively. Only trial 1 (12.5 deg) and trial 7

Table 4 Slipstream trial run constants

\begin{tabular}{ccccccc}
\hline \hline Trial & $M$ & $\alpha$ & $\delta_{c}$ & $\delta_{e}$ & $t$ & Slipstream impact location \\
\hline $1 \mathrm{~s}-6 \mathrm{~s}$ & 8.00 & $2.50 \mathrm{deg}$ & $10.0 \mathrm{deg}$ & $5.00 \mathrm{deg}$ & 0.00 & $42 \%$ down chord length \\
\hline \hline
\end{tabular}




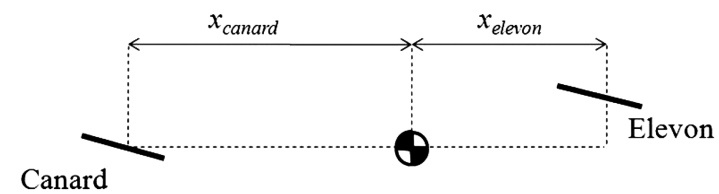

Fig. 19 Geometry used for moment calculations.

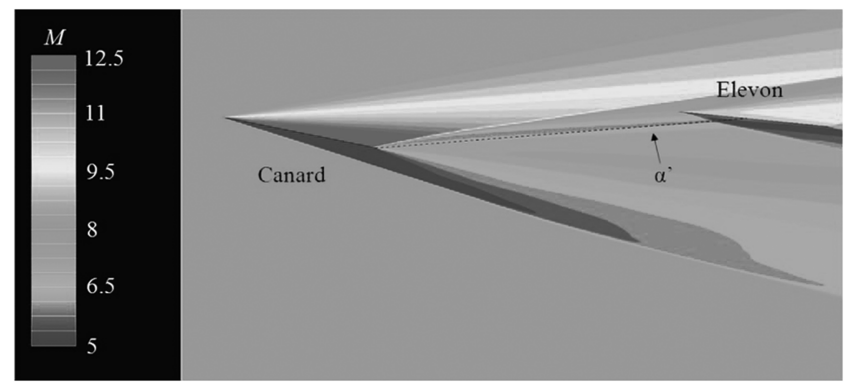

Fig. 20 Mach contours for canard-elevon horizontal distance $3 c$.

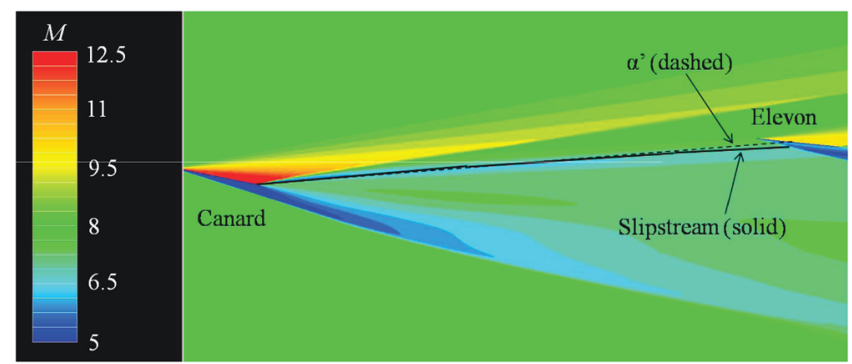

Fig. 21 Mach contours for canard-elevon horizontal distance 7c.

(12.1 deg) had larger canard wedge angles, but trial 1 had a lower Mach number. The earlier analytical calculations showed that, as the Mach number and canard wedge angle increase, the flow behind the canard deviates more from the freestream flow. These results show that this agreement holds true for a computational Euler solution of the flowfield.

\section{Other Interaction Effects}

Looking at the results in Table 7, trial 7 has the largest percent error for both the flat plate (17.6\%) and thickness (52.9\%) formulations.

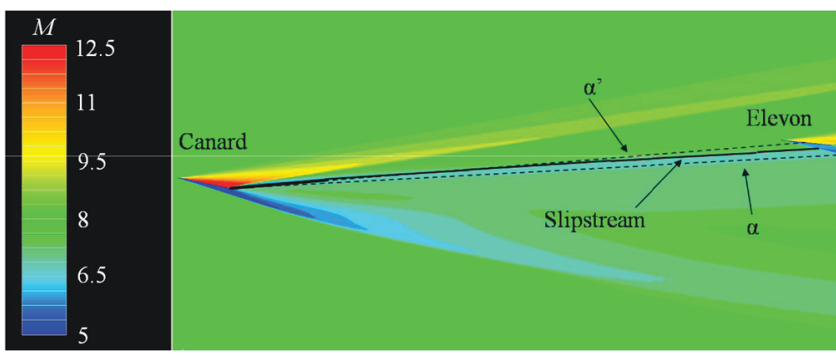

Fig. 22 Mach contours for canard-elevon horizontal distance $12 c$.

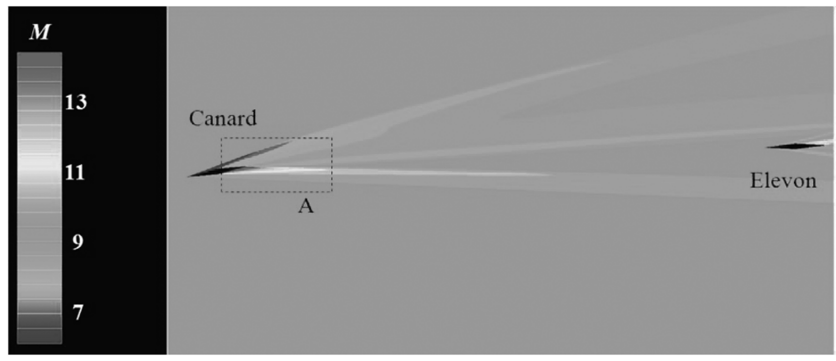

Fig. 23 Mach contours of trial 11.

The reason for these large differences becomes apparent when looking at the pressure contours of this trial, as shown in Fig. 25.

The shock/expansion fan system from the top of the canard travels downstream and impacts the elevon. The analytical formulation does not take into account the possibility of shocks and expansion fans directly impacting the elevon. As a result, the effectiveness predictions for situations when this occurs will not be as accurate. This was the only test matrix trial in which this situation was encountered. Therefore, if this run is not included in the mean and standard deviation calculations, the new values, again in terms of the compound value of the error, are as shown in Table $\underline{8}$. Also, note that the improvement in the table is the absolute amount by which the percent error improved, and "thickness" and "flat plate" refer to the analytical formulations assuming thickness and flat plate, respectively.

\section{Slipstream Trial Results}

Figure 26 is a plot of the elevon effectiveness ratio of the trials detailed in Table $\underline{5}$ as a function of the horizontal canard-elevon distance. In this section, side A refers to the side of the slipstream impacting the front of the elevon (see Fig. 13). Before this research,

Table 7 Elevon effectiveness ratio results

\begin{tabular}{|c|c|c|c|c|c|}
\hline \multirow[b]{2}{*}{ Trial } & \multicolumn{3}{|c|}{ Elevon effectiveness ratio } & \multirow[b]{2}{*}{$\%$ error: thick } & \multirow[b]{2}{*}{$\%$ error: fla } \\
\hline & CFD & Analytical, thick & Analytical, flat & & \\
\hline 1 & 0.949 & 0.908 & 0.928 & 4.36 & 2.29 \\
\hline 2 & 0.988 & 0.984 & 0.984 & 0.445 & 0.445 \\
\hline 3 & 0.958 & 0.973 & 0.987 & -1.57 & -3.10 \\
\hline 4 & 0.930 & 0.997 & 1.00 & -7.22 & -7.56 \\
\hline 5 & 0.972 & 0.970 & 0.991 & 0.257 & -1.90 \\
\hline 6 & 0.979 & 0.993 & 0.995 & -1.45 & -1.66 \\
\hline 7 & 0.772 & 0.364 & 0.636 & 52.9 & 17.6 \\
\hline 8 & 0.762 & 0.781 & 0.782 & -2.56 & -2.64 \\
\hline 9 & 0.992 & 0.991 & 0.999 & 0.111 & -0.695 \\
\hline 10 & 0.892 & 0.781 & 0.909 & 12.4 & -1.86 \\
\hline 11 & 0.993 & 0.617 & 0.938 & 37.9 & 5.59 \\
\hline 12 & 0.728 & 0.639 & 0.715 & 12.3 & 1.89 \\
\hline 13 & 0.884 & 0.874 & 0.944 & 1.08 & -6.79 \\
\hline 14 & 0.965 & 0.996 & 1.00 & -3.18 & -3.60 \\
\hline 15 & 0.961 & 0.988 & 0.998 & -2.80 & -3.78 \\
\hline 16 & 0.975 & 0.928 & 0.941 & 4.84 & 3.47 \\
\hline \multirow[t]{2}{*}{17} & 0.924 & 0.970 & 0.979 & -5.03 & -5.94 \\
\hline & \multicolumn{3}{|c|}{$\begin{array}{l}\text { Compound mean: } \\
\text { Compound standard deviation: }\end{array}$} & 8.85 & 4.17 \\
\hline
\end{tabular}




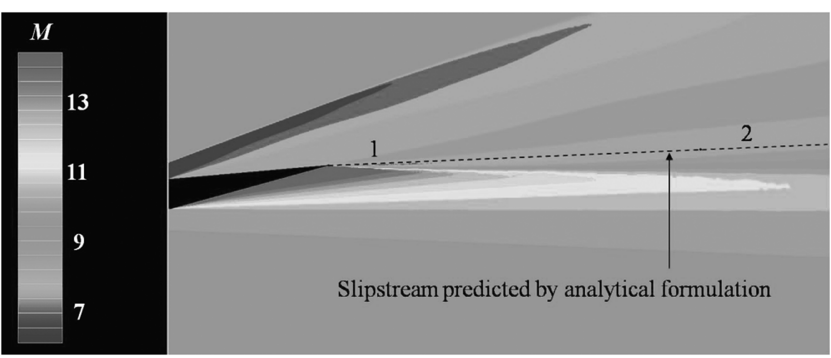

Fig. 24 Close-up of Mach contours for trial 11.

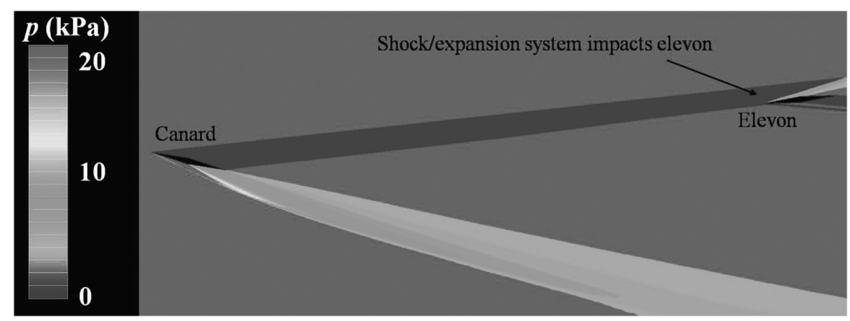

Fig. 25 Pressure contours for trial 7.

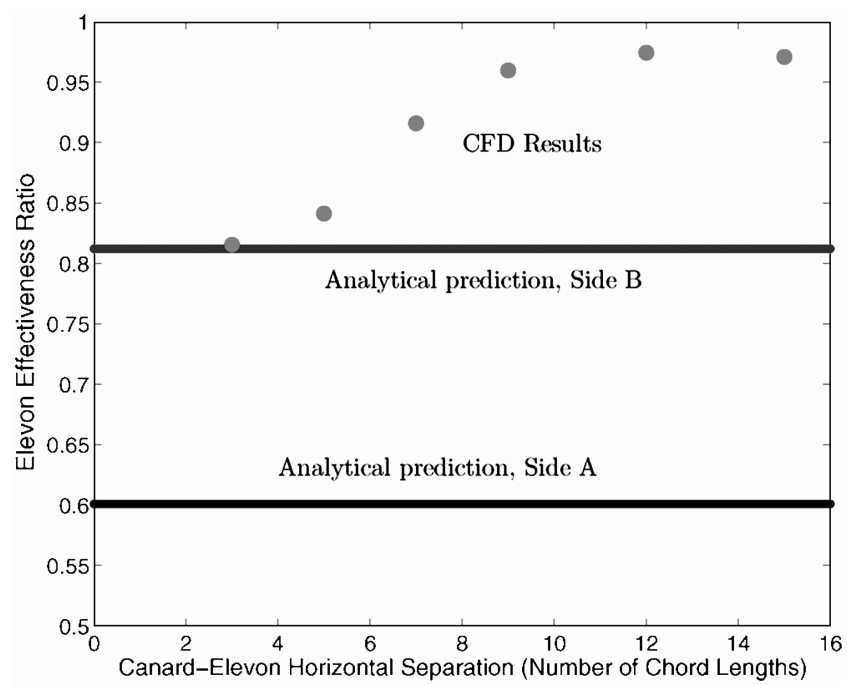

Fig. 26 Impact of the distance between canard and elevon on the elevon performance.

the flow conditions on this side were used any time the slipstream impacted the elevon. Side B is the opposite side of the slipstream.

Table 9 shows the percent error between the CFD-calculated elevon effectiveness ratios and those calculated by the analytical formulations considering the two flow conditions: side A and side B of the slipstream. From Fig. 26 and Table 9, it is clear that the effect of the slipstream on the elevon diminishes with increasing canardelevon distance. In fact, by the time the horizontal distance reaches 12 chord lengths, the effectiveness ratio has almost returned to its freestream value of 1 (note that, at 15 chord lengths, there is a decrease of $0.4 \%$ from the value at 12 chord lengths that is attributed to numerical variations on the CFD grid and does not alter the conclusion). Also, for each case, side B proved to be the closer approximation; in fact, at a horizontal distance of 3 chord lengths, the error with respect to the CFD trial was less than $1 \%$. For these trials,

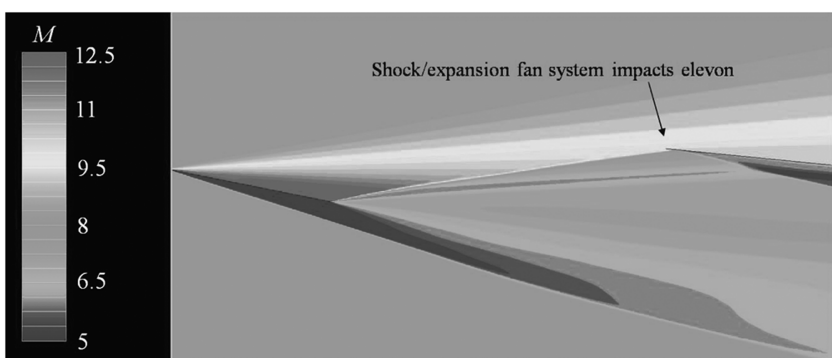

Fig. 27 Expansion fan-elevon interactions, trial A2.
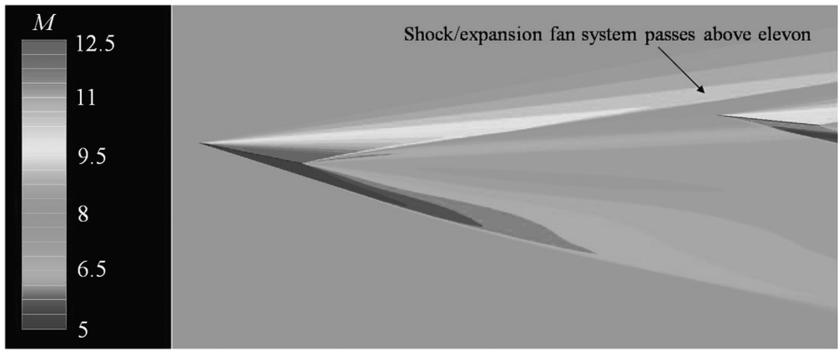

Fig. 28 Expansion fan-elevon interactions, trial A3.

the slipstream struck the elevon about $42 \%$ of the way down its chord length, meaning that, if the slipstream were to continue all the way to the airfoil surface, more of the surface would see flow from side B (beneath the slipstream) than side A (above the slipstream).

To see how the effectiveness ratio changes depending on where the slipstream strikes the surface, three additional trials were conducted; they are summarized in Table 10. Note that, for the slipstream-elevon intersection point, $100 \%$ would refer to the slipstream striking the trailing edge of the elevon. Table 11 summarizes the results in terms of the errors encountered by the analytical formulation.

From Table 11, side B agrees with the CFD results much more closely than side A for trial A1, which is consistent with the earlier observation. For trial A2, side A agrees much more closely. However, for this trial, the shock/expansion fan system from the canard directly interferes with the elevon. Figure 27 displays the Mach contours for this situation.

Trial A3 was conducted to help determine the impact of the shock/ expansion fan system on the elevon effectiveness ratio. By moving slightly further downstream, the elevon was able to be positioned at a location such that the slipstream would still strike very close to the back, thereby theoretically allowing flow on side A to impact much of the elevon while still keeping the elevon out of the canard's shock/ expansion fan system, as shown in Fig. 28.

Neither one of the analytical formulation predictions came within $10 \%$ of the CFD value. This is possibly due to two factors. The first,

Table 9 Slipstream trial errors with respect to CFD results

\begin{tabular}{lcc}
\hline \hline $\begin{array}{c}\text { Canard-elevon } \\
\text { horizontal distance }\end{array}$ & $\begin{array}{c}\text { \% error, } \\
\text { side A }\end{array}$ & $\begin{array}{c}\text { \% error, } \\
\text { side B }\end{array}$ \\
\hline $3 c$ & 26.2 & 0.340 \\
$5 c$ & 28.5 & 3.49 \\
$7 c$ & 34.4 & 11.4 \\
$9 c$ & 37.1 & 15.0 \\
$12 c$ & 38.4 & 16.7 \\
$15 c$ & 38.1 & 16.4 \\
\hline \hline
\end{tabular}

Table 8 Compound mean error and standard deviation without considering trial 7 results

\begin{tabular}{lcccc}
\hline \hline & Thickness & Flat plate & Improvement, thick. & Improvement, flat. \\
\hline Mean & 6.10 & 3.33 & 2.75 & 0.840 \\
Standard deviation & 9.30 & 2.13 & 4.89 & 1.90 \\
\hline \hline
\end{tabular}


Table 10 Additional slipstream trial parameters

\begin{tabular}{lccc}
\hline \hline Trial & Horizontal distance & Vertical distance & Slipstream-elevon intersection point \\
\hline A1 & $3 c$ & $0.110 c$ & $66 \%$ \\
A2 & $3 c$ & $0.150 c$ & $91 \%$ \\
A3 & $5 c$ & $0.280 c$ & $86 \%$ \\
\hline \hline
\end{tabular}

Table 11 Additional slipstream trial results

\begin{tabular}{lccc}
\hline \hline Trial & CFD elevon effectiveness ratio & \% error, side A & \% error, side B \\
\hline A1 & 0.829 & 27.4 & 1.99 \\
A2 & 0.609 & 1.35 & -33.2 \\
A3 & 0.917 & 34.5 & 11.5 \\
\hline \hline
\end{tabular}

as mentioned earlier, is that the flow properties move closer to freestream property values as the perpendicular distance away from the freestream increases. Because the slipstream is striking the very back of the elevon, it is possible that the front and middle are experiencing flow that has much different properties. The second factor is that, although the shock/expansion fan system does not directly strike the elevon, its close proximity could have some effect on how far the slipstream effects propagate into the flowfield.

\section{Conclusions}

Of the two analytical formulations, the numerical technique provided the more reasonable answers over a wider range of Mach number/wedge angle combinations than did the series technique. Calculations showed that the effect on the elevon was significant at certain flight conditions. Thus, the numerical technique was the analytical formulation used to compare with the CFD results.

The CFD results have shown that, for an Euler solution, the slipstream behind the trailing edge of an airfoil does in fact impact the control effectiveness of the elevon. Trial runs showed that the slipstream's effect on the elevon diminishes with increased distance away from the airfoil, suggesting that interactions with near-freestream flow conditions serve to weaken it. By a canard-elevon separation of 12 chord lengths, the flow impacting the elevon, as measured by the elevon effectiveness ratio, had very nearly returned to freestream. This assertion is also supported by the fact that the slipstream begins to curve as it moves downstream to an angle closer to $\alpha$ than $\alpha^{\prime}$. However, its initial angle is closer to the predicted $\alpha^{\prime}$.

Overall, the elevon effectiveness ratios predicted by the analytical formulation assuming flat plate airfoils were closer to the CFD results than the formulation with thickness effects included. Though for a few cases the thickness corrections provided results that more closely matched the CFD data, the overall error for both the flat plate and thickness calculations for these cases was relatively small, as detailed in Sec. VII.A. The Mach numbers directly above and below the slipstream predicted by the analytical formulation with thickness corrections are less than those predicted with the flat plate assumption and decrease as thickness increases. However, the CFD results showed that these relatively low Mach numbers were very localized effects just behind the trailing edge that dissipated quickly. Therefore, using the flow properties obtained through the thickness correction does not improve the predictive accuracy of the analytical formulation, and the simple flat plate representation of the airfoil may be used.

When the slipstream impacted the airfoil, the elevon effectiveness ratios predicted by using the conditions on side $\mathrm{B}$ (the flow not hitting the tip of the elevon) were generally closer than those predicted by using the conditions on side $\mathrm{A}$. The only case in which the prediction using side A was closer was trial A2, which had a canard-elevon separation of three chord lengths; the slipstream impacted the elevon around $90 \%$ of the way down the chord. However, the Mach contour plot (Fig. 27) revealed that, at that location, the elevon was impacted by the shock/expansion fan system from the canard. When moved back to a five chord length separation, with the slipstream hitting the same location, side B provided the closer prediction. In Fig. 27, notice that the slipstream and shock/expansion system from the canard are relatively close to each other. The slipstream has its greatest effect on the elevon in conditions such as this, which have a relatively small canard-elevon separation. Therefore, in these conditions, when the slipstream impinges on the trailing edge of the elevon, the front of the elevon will either be in or very near to the shock/expansion fan system from the canard. Because of this, the analytical formulation prediction is not valid, as it does not take these shock/expansion fan system effects into consideration. As a result, for cases in which the slipstream strikes the elevon, side B should be used in the analytical formulation.

\section{Acknowledgments}

The authors acknowledge the help provided by Nathan Scholten (University of Michigan) with the CFD study. This work was supported in part by a grant of computer time from the Department of Defense High Performance Computing Modernization Program at U.S. Air Force Research Laboratory Major Shared Resource Center. Funds for the Michigan-U.S. Air Force Research Laboratory Collaborative Center in Control Science were made available from the Air Force Research Laboratory/Air Vehicles Directorate grant FA 8650-07-2-3744.

\section{References}

[1] Kahane, A., and Lees, L., "The Flow at the Rear of a Two-Dimensional Supersonic Airfoil," Journal of the Aeronautical Sciences, March 1948, pp. 167-170.

[2] Lighthill, M. J., "The Conditions Behind the Trailing Edge of the Supersonic Airfoil," Aeronautical Research Council Reports and Memoranda No. 1930, 1944, pp. 249-256.

[3] Busemann, A., "Aerodynamischer Auftrieb bei Uberschallgeschwindigkeit," Luftfahrtforschung, Vol. 12, No. 6, 1935.

[4] Oppenheimer, M. W., Skujins, T., Bolender, M. A., and Doman, D. B., "A Flexible Hypersonic Vehicle Model Developed with Pistion Theory," AIAA Paper 2007-6396, Aug. 2007.

[5] "Equations, Tables, and Charts for Compressible Flow," National Advisory Committee for Aeronautics, Tech. Rept. NACA-1135, Ames Aeronautical Laboratory, Moffett Field, CA, 1953.

[6] Anderson, J. D., Fundamentals of Aerodynamics, McGraw-Hill, New York, 1984.

[7] Hilton, W., High-Speed Aerodynamics, Longmans, Green, and Co., New York, 1951.

[8] “CFD++ User Manual," Metacomp Technologies, Agoura Hills, CA, 2008.

[9] “Gridgen User Manual,” Ver. 15, Pointwise, Inc., Fort Worth, TX, 2007.

[10] Tang, B., "Orthogonal Array-Based Latin Hypercubes," Journal of the American Statistical Association, Vol. 88, No. 424, 1993, pp. 1392 1397. doi: $10.2307 / 2291282$

[11] Cioppa, T. M., and Lucas, T. W., "Efficient Nearly Orthogonal and Space-Filling Latin Hypercubes," Technometrics, Vol. 49, No. 1, 2007, pp. $45-55$. doi:10.1198/004017006000000453 